\author{
M. K. Budzik ${ }^{1,2}$, R. Pilawka ${ }^{3}$, K. Imielińska ${ }^{1}$, J. Jumel ${ }^{2}$, M. E. R. Shanahan ${ }^{2}$ \\ ${ }^{1}$ Gdańsk University of Technology, Materials Science \& Engineering Department, Narutowicza \\ 11/12, 80-233 Gdańsk, Poland \\ ${ }^{2}$ Universite Bordeaux 1, Laboratoire de Mecanique Physique, 351 Cours de la \\ Liberation, 33-405 Talence-Cedex, France \\ ${ }^{3}$ West Pomeranian University of Technology in Szczecin, Polymer Institute ul. Pułaskiego 10, \\ 70-322 Szczecin, Poland
}

\title{
FRACTURE OF ALUMINIUM JOINTS BONDED WITH EPOXY ADHESIVE REINFORCED BY MMT NANOPARTICLES
}

\begin{abstract}
Crack propagation behavior was studied for aluminium/aluminum adhesive joints bonded with two epoxy adhesives: pure and reinforced with clay nanoparticles. The focus was also on the novel use of the constant displacement rate test to study adhesion/adhesives efficiency. The epoxy systems studied were: Epidian E6 produced from bisphenol A and epichlorohydrin, ("Organika -Sarzyna" Poland); pure or strengthened with montmorillonit nanoparticles (MMT). Crack growth rate was estimated for two displacement rates. The nanoparticle reinforced epoxy showed advantage over pure epoxy adhesive (Figs. $4,5)$. This effect was more pronounced at low deflection rates. The constant displacement rate test was found promising to study microstructural effects in adhesive joints.
\end{abstract}

Key words: Epoxy adhesive, Nano clay, Nanofiller, Montmorillonite, Fracture

\section{INTRODUCTION}

Adhesive bonding is rapidly developing for many applications in: aviation, electrical, automotive and marine industries, building engineering, medicine (dentistry). Increases in specific strength, corrosion resistance plus possibility of joining different materials are the principal advantages of adhesive joints over the 'traditional' joining methods (riveting, bolting, welding, brazing). Naturally there is still need to increase mechanical properties and durability of adhesives [1-5]. The most popular adhesives used in structural applications are epoxies, which promise strong, resistant and durable joints. One possibility to increase adhesives mechanical properties is to reinforce them with nanoparticles. In the literature [6-8] we can find information about the influence of different nanoparticles on strength and durability of the joints. However, whereas the majority of the researchers compare static loading behavior in shear lap joints, only few consider the fracture mechanics approach and almost none address fracture in slow, constant displacement rate conditions.

Among the many fracture mechanics tests used to assess adhesive bonding efficiency, the most commonly used are those based on cantilever beam, e.g. compact tension 
(CT), the wedge test and DCB (Double Cantilever Beam). DCB test can be performed according to the loading mode in different configurations: with applied constant stress (TDCB), applied constant displacement rate (CRT), constant force, or imposed constant displacement (Wedge Test) [9-14]. In this study we have analyzed, at a slow displacement rate, the mechanical behavior of joints prepared using DGEBA epoxy resin, and the same resin filled with 1 - D, organic particles of MMT. Advantage of clay reinforcement is that the particles are natural, and thus, environment- friendly, which can be a very important criterion nowadays. They are also much lighter then nonorganic particles, and are likely to increase strength of the joints.

The aim of this study was to compare crack propagation behavior of the aluminium/aluminium adhesive joints bonded with two epoxy adhesives: pure and reinforced with clay nanoparticles. The focus was also on the novel use of the constant displacement rate test to study adhesion/adhesives efficiency.

\section{EXPERIMENTAL PROCEDURE}

\section{Materials and specimen preparation}

Two different aluminium plates were bonded using two different epoxy adhesive systems. The size and geometry of the specimens are shown in Fig. 1. Aluminum alloys used were: AA $2024(\mathrm{Al}-\mathrm{Cu})$ (upper, flexible plate, $\mathrm{h}=1,6 \mathrm{~mm})$ and AA $5754(\mathrm{Al}-\mathrm{Mg}$ ) (lower, rigid plate, $\mathrm{h}=6 \mathrm{~mm}$ ). Relative flexural rigidity of the plates is governed by the ratio of the cubes of thickness multiplied by appropriate modulus, thus giving $\mathrm{H}^{3} \mathrm{E}_{\mathrm{H}} / \mathrm{h}^{3} \mathrm{E}_{\mathrm{h}} \sim 62$, where $\mathrm{H}$ and $\mathrm{h}$ corresponds to Fig. 1. Thus, assuming Young moduli of the plates: 60 and $70 \mathrm{GPa}$ for upper and lower plates respectively, the terms "flexible" and "rigid" are permitted for 1,6 $\mathrm{mm}$ and $6 \mathrm{~mm}$ plates. The plates were bonded along $1=70 \mathrm{~mm}$ with two adhesive systems: 1/epoxy resin - Epidian ${ }^{\circledR} 6$, (abbreviated to E6,) produced from DGEBA (Diglycidyl ether of bisphenol-A: typical commercial epoxy resin synthesized by reacting bisphenol-A with epichlorohydrin in presence of a basic catalyst) supplied by Chemical Works "Organika -Sarzyna" S.A. in Nowa Sarzyna, Poland. The epoxy equivalent weight EEW was $188 \mathrm{~g}$ /equiv. and the average molecular weight $-\mathrm{n} \leq 700$. The hardener was butyloimidazole, in proportion 100:1. The second system was the same resin reinforced with $5 \%$ of 1-D montmorillonit nanoparticles, (MMT) $\left(\mathrm{Al}_{2}\left[(\mathrm{OH})_{2} \mathrm{Si}_{4} \mathrm{O}_{10}\right] \cdot n \mathrm{H}_{2} \mathrm{O}\right)$. Nanoparticles were dispersed and spread in the resin using ultrasonic sound $(\mathrm{f}=0.5 \mathrm{~Hz}$ ). Prior to bonding plates were degreased, abraded, and electrochemically treated with PAA (Phosphoric Acid Anodizing) (10\% wt. $\mathrm{H}_{3} \mathrm{PO}_{4}, 20$ minutes, ambient conditions, DC $10 \mathrm{~V}$, contrelectrode Ti grid) [15]. Bondline thickness for all samples was $600 \mu \mathrm{m} \pm 40$ (measured with optical microscope). The PTFE foil spacers were added to prevent bonding at joint extremities. The adhesive was crosslinked at a constant pressure of 2 atmospheres at $120^{\circ} \mathrm{C}$ for 60 minutes and slowly cooled in the oven. Before the test samples were precracked by insertion of the wedge between two bonded plates. 


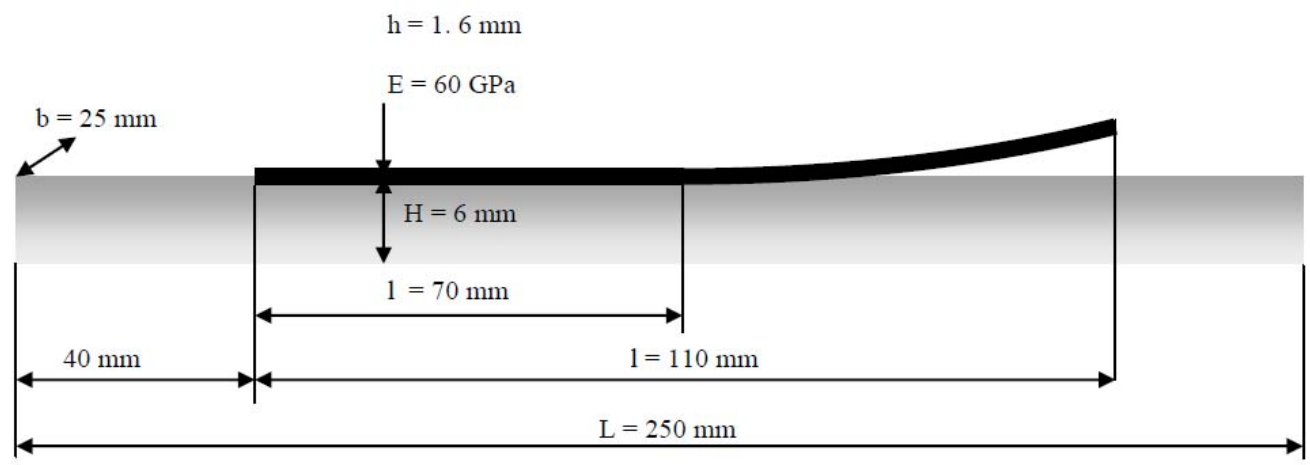

Fig. 1. Specimen size and geometry

\section{Constant Rate Test (CRT)}

The constant displacement rate test (CRT) [14] was performed using 'low displacement rate' tensile machine which was adopted to run the mode I fracture test. Crack propagation and fracture energy were estimated. These parameters depend on the force (F) and plate deflection $(\Delta)$ measurements obtained from force and displacement sensors. The force sensor was Instron with $200 \mathrm{~N}$ capacity and displacement sensor Peltron PSzl with $20 \mathrm{~mm}$ range. The location of the sensors was linear, thus the displacement was measured along the acting force. The force and displacement vs time were recorded (Fig. 2). The temperature during tests was $20 \pm 2^{\circ} \mathrm{C}$, and ca. $55 \pm 5 \% \mathrm{RH}$. Two displacement/deflection rates were used; $\mathrm{v}_{\mathrm{D}}=0.485 \mathrm{mmh}^{-1}$ - 'fast', and $\mathrm{v}_{\mathrm{D}}=0.248 \mathrm{mmh}^{-1}$ - 'slow' (corresponding numbers I and II respectively) for both adhesive systems.

All results were supported with macro (Digital Camera Canon D 40) and microoptical (Leica MEF $4 \mathrm{M}$ with Canon Power Shot G5) views of fractured surfaces.

\section{The principles of crack propagation and fracture energy measurements.}

Before going into details of the test results it is useful to analyse the basic principles of the technique employed in this study.

In order to asses crack length (a), and fracture energy $\left(\mathrm{G}_{\mathrm{I}}\right)$, force $(\mathrm{F})$, and loaded plate deflection $(\Delta)$ were measured. The following analysis is proposed to assess fracture behavior.

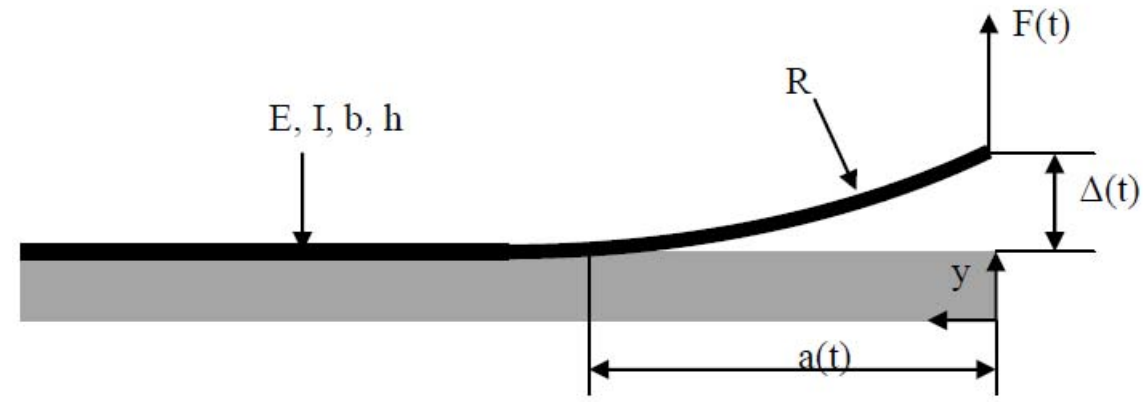

Fig. 2. The Constant Rate Test (CRT) model 
From general fracture mechanics relation, primarily established and known as IrwinKies equation [16]:

$\mathrm{G}=\frac{\mathrm{F}^{2}}{2 \mathrm{~b}} \frac{\mathrm{dC}}{\mathrm{da}}$

$\mathrm{G}$ - energy release rate, work of adhesion $\left(\mathrm{J} \mathrm{m}^{-2}\right)$

C compliance -

$$
\mathrm{C}=\frac{\Delta}{\mathrm{F}}
$$

Now consider simple beam model, from which deflection (corresponding to Fig. 6), is given by:

$$
y(x-0)-\Delta-\frac{F a^{3}}{3 E I}
$$

Noting that $\mathrm{I}=\mathrm{bh}^{3} / 12$, we obtain crack position, for any given, $\mathrm{F}$ and $\Delta$.

$$
a=h \sqrt{\frac{\mathrm{Eb} \Delta}{4 \mathrm{~F}}}
$$

Finally, combining previous equations, we can write formula for fracture energy, $G_{I}$ :

$$
\mathrm{G}_{1}=\frac{3 \mathrm{~F}}{\mathrm{bh}} \sqrt{\frac{F \Delta^{2}}{2 \mathrm{bE}}}
$$

\section{Results and discussion}

The plate deflection- time characteristics corresponding to two displacement rates and two epoxy adhesive systems are shown in Fig. 3. To be noted is the significant difference in the deflection of the plate at higher and lower displacement rates. No material effect was observed, the deflection time plots for the pure epoxy adhesive specimen and one in which epoxy was reinforced with nanoparticles are almost the same at one displacement rate. However, crack growth rate in the adhesive joints was evidently dependant on the adhesive system used to bond the plates. 


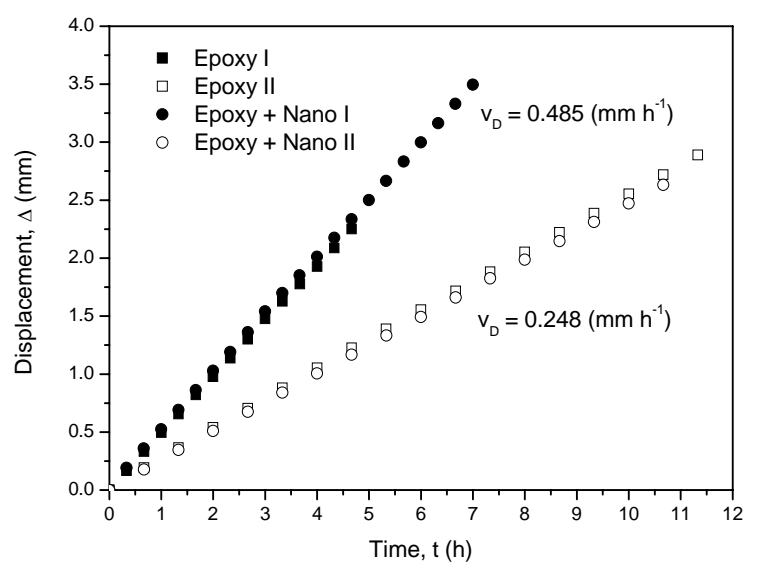

Fig. 3. Specimen deflection vs time for two adhesive systems and two displacement rates

Crack propagation plots are shown in Figs. 4ab. To be noted are: nonlinear graph profile (circle, Fig. 4b) followed by quasi-constant crack growth $\left(\mathrm{v}_{\mathrm{c}}=\right.$ const.) and distinct difference in the behavior of the two material systems at lower displacement rate (constant crack growth rate regime). Crack growth rate of the Epoxy + Nano II (lower displacement rate) specimens is markedly lower than one of the pure resin samples.

(a)

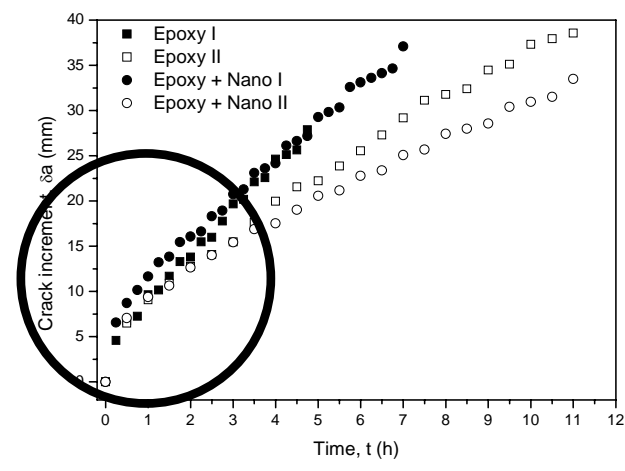

Fig. 4. Crack increment vs time plots. Nonlinear graph profile (circle) followed by quasi-constant crack growth $\left(v_{c}=\right.$ const. $)(a, b)$. Nonlinear part of the graph at the onset of crack growth $(t=0-1,5 h(b)$

The advantage of the epoxy system strengthened with nanoparticles over pure epoxy adhesive is illustrated in Figs. 5,6 showing the average minimum fracture energy and crack growth rate vs strain rate for the two adhesive joints studied in this work. To be noted (Fig. 6) is the importance of the low strain rate in this study to show microstructural effect which is also confirmed by microscopic fracture examination. 


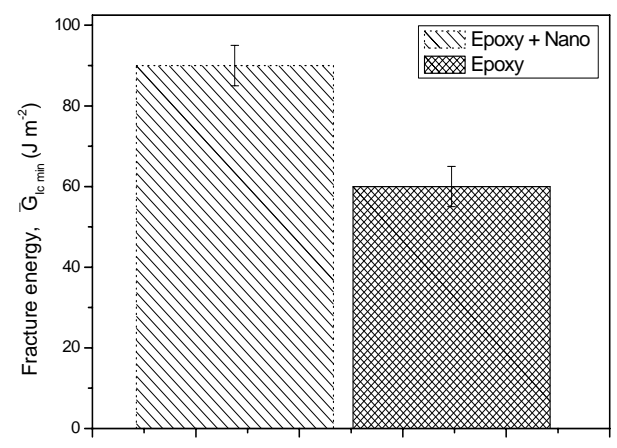

Fig. 5. Average minimum fracture energy for aluminium bonded with reinforced and pure epoxy adhesive

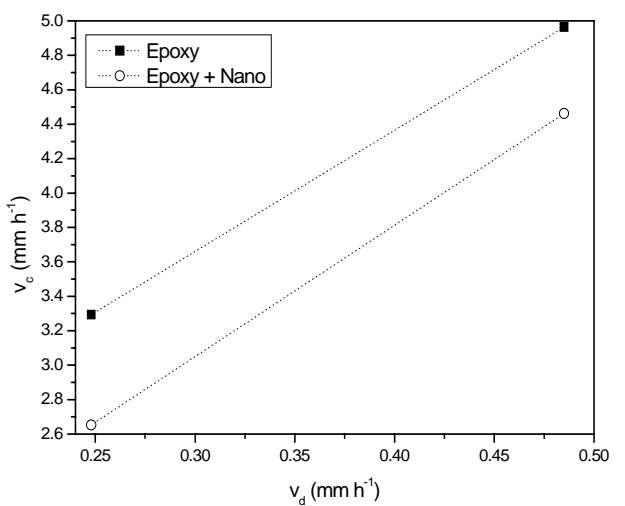

Fig. 6. Crack growth rate vs deflection rate for the two systems: with and without nanoparticles

The illustration of fracture surfaces is shown in Figs. 7,8 for the two epoxy systems at lower and higher strain rates. The centre of the specimens was selected for optical examination. No difference in the fracture surface profile of the two adhesive systems was noted for the same strain rate. The magnification (200x) was too low. However, there is a marked difference in the appearance of fracture surfaces depending on the crack growth rate for both materials. The higher the deflection rate the coarser the fracture surface which implies that microstructural effects are more present at lower deflection rate (fine fracture surface). Accordingly, very slow deflection rate is recommended in further study of microstructural effects. The explanation is time dependant nature of the mechanical properties of epoxy-based materials. Accesively high deflection rate does not allow micromechanical effects to take place.
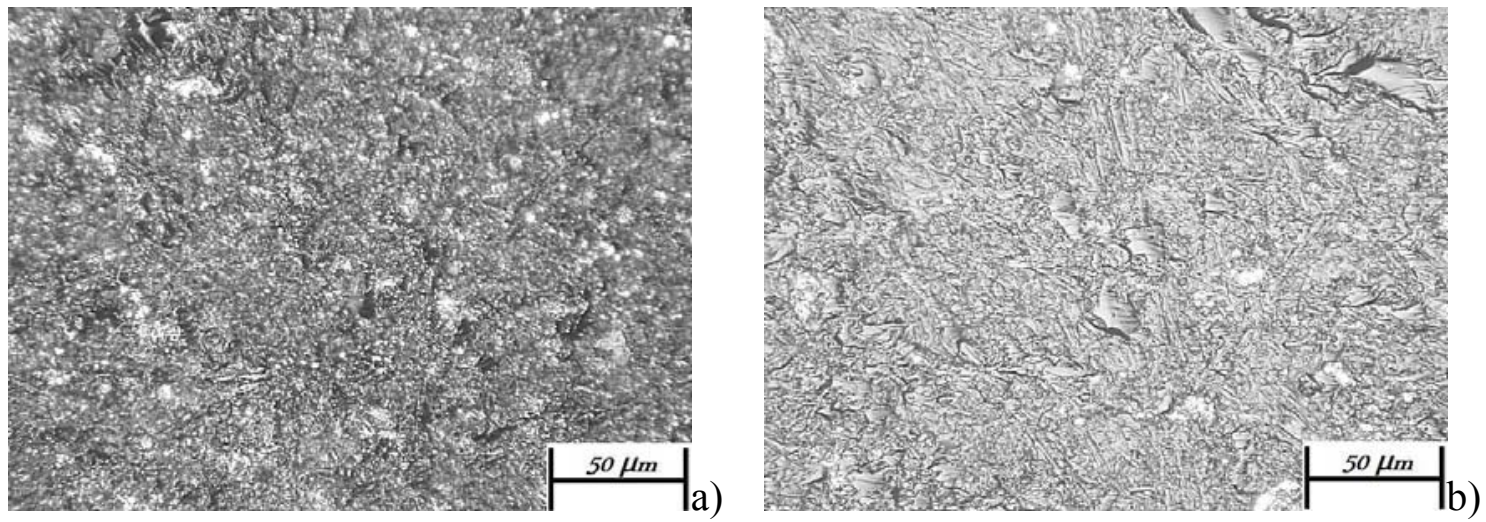

Fig. 7. Optical micrographs of fracture surface of E6 resin, after lower a) and higher crack growth rate(b)

The mechanism of adhesive strengthening by nanoparticles, was not studied in this work. It was reported before, e.g. [17,18]. In our work we were rather concentrated on the use of constant displacement rate test which promises to give advantages over experiments run instantly. By choosing right parameters of the test especially a very low displacement rate we should be able to study the environmental effects i.e. degradation of the adhesive joint in the hostile environment. 

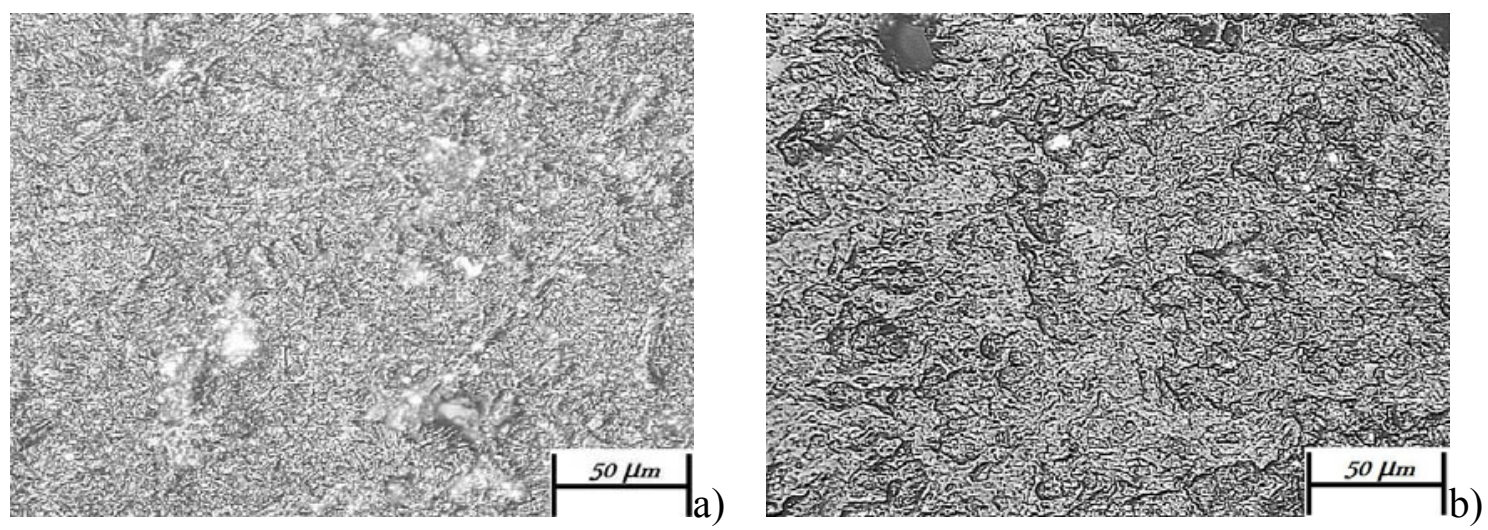

Fig. 8. Optical micrographs of fracture surface of E6 with nanoparticles, after lower (a) and higher crack growth rate (b)

\section{CONCLUSIONS}

Crack propagation behavior was compared for the aluminium/aluminum adhesive joint bonded with two epoxy adhesives: pure and reinforced with clay nanoparticles. The novel use of the Constant Rate Test (CRT) with slow displacement rate was explored. The following conclusions are drawn:

1. The constant rate test was found sensitive enough to study microstructural effects in the adhesive joints

2. The clay nanoparticle-modified epoxy adhesive gives higher fracture energy as well as smaller crack growth rate over the pure adhesive.

3. Crack propagation rate and fracture energy of the adhesive joint are deflection rate dependant.

4. The advantage of the epoxy/nanoparticle reinforced system is more exposed when plate deflection rates used in the test are low.

\section{REFERENCES}

1. Y.Miyano, M.Nakada, J.Ichimura, E.Hayakawa. Accelerated testing for long-term strength of innovative CFRP laminates for marine use. Composites: Part B 39 (2008) pp.5-12.

2. R. Sarathi, P. Rajesh Kumar, R.K. Sahu: Analysis of surface degradation of epoxy nanocomposite due to tracking under AC and DC voltages. Polymer Degradation and Stability 92 (2007) pp.560-568.

3. K.B. Armstrong: Long-term durability in water of aluminium alloy adhesive joints bonded with epoxy adhesives. International Journal of Adhesion \& Adhesives 17 (1997) pp. 89-105. 
4. S.Xua, D.A. Dillard, J.G. Dillard: Environmental aging effects on the durability of electrically conductive adhesive joints. International Journal of Adhesion \& Adhesives 23 (2003) pp.235-250.

5. A. Mukherjee, G.L.Rai: Performance of reinforced concrete beams externally prestressed with fiber composites. Construction and Building Materials, 23 (2009) pp.822-828.

6. L.L. Zhai, G.P. Ling, Y.W. Wang: Effect of nano- $\mathrm{Al}_{2} \mathrm{O}_{3}$ on adhesion strength of epoxy adhesive and steel. International Journal of Adhesion \& Adhesives 28 (2007) pp. 23-28.

7. H.Zhang, L.C.Tang, Z.Zhang, K.Friedrich, S.Sprenger: Fracture behaviours of in situ silica nanoparticle-filled epoxy at different temperatures. Polymer 49 (2008) pp. 3816-3825.

8. B.C.Kim, S.W.Park, D.G.Lee: Fracture toughness of the nano-particle reinforced epoxy composite. Composite Structures 86 (2008) pp. 69-77.

9. A.V.Pocius, EditorP: Adhesion Science and Engineering: I. The mechanics of adhesion,

10. B.R.K.Blackman, A.J.Kinloch, M.Paraschi, W.S.Teo: Measuring the mode I adhesive fracture energy, GIC, of structural adhesive joints: the results of an international round-robin. International Journal of Adhesion \& Adhesives 23 (2003) pp. 293-305.

11. M.Budzik, J.Jumel, K.Imielińska and M.E.R.Shanahan: Accurate and continuous adhesive fracture energy determination using an instrumented Wedge test. International Journal of Adhesion \& Adhesives (2009).

12. C.Sun, M.D.Thouless, A.M.Waas, J.A.Schroeder, P.D.Zavattieri: Rate effects for mixed-mode fracture of plastically-deforming, adhesively-bonded structures. International Journal of Adhesion \& Adhesives 29 (2009) pp.434-443.

13. R.Gensler, C.J.G. Plummer, C.Grein, H.-H.Kausch: Influence of the loading rate on the fracture resistance of isotactic polypropylene and impact modified isotactic polypropylene. Polymer 41 (2000) pp. $3809-3819$.

14. C.Xu, T.Siegmund, K.Ramani: Rate-dependent crack growth in adhesives II. Experiments and analysis. International Journal of Adhesion \& Adhesives 23 (2003) pp.15-22.

15. Phosphoric Acid Anodizing can be performed in accordance with Guide D 3933.

16. A.S.Tetelman, A.J.McEvily: Fracture of structural materials. Jr. John Wiley and Sons, inc. 1967.

17. G.Schmid Editor: Nanoparticles. Theory and applications. Wiley-Vch Verlag $\mathrm{CmbH}$ \& Co. KCaA, 2004.

18. Pilawka R., Spychaj T.: Kleje epoksydowe z nano-cząstkami do łączenia metali. Kompozyty (Composites) 4(2004) Nr 9, pp. 61-67. 